\title{
A Novel CPW-Fed UWB Antenna with Band-Stop Function
}

\author{
Huaming Chen, Zhengrong Li, Baiyu Li, and Guangfu Sun \\ College of Electronic Science and Engineering, National University of Defense Technology, Changsha 410073, China \\ Correspondence should be addressed to Huaming Chen; chenhuaming@yeah.net
}

Received 26 August 2014; Accepted 13 October 2014; Published 9 November 2014

Academic Editor: Jit S. Mandeep

Copyright (C) 2014 Huaming Chen et al. This is an open access article distributed under the Creative Commons Attribution License, which permits unrestricted use, distribution, and reproduction in any medium, provided the original work is properly cited.

\begin{abstract}
A novel coplanar waveguide-fed (CPW) ultrawideband (UWB) antenna with band-stop function is presented in this paper. The proposed antenna comprises a CPW-fed slot rectangular patch with an open stub ground plane, and two inverted L-shaped strip conductors are fabricated on the back plane. The overall size of the antenna is $25 \times 25 \times 1.6 \mathrm{~mm}^{2}$, and it achieves good impedance matching and radiation gain. Simulated and measured results show that the designed antenna operates at $2.9 \mathrm{GHz}-13.08 \mathrm{GHz}$ with band rejection in the frequency band of $7.7 \mathrm{GHz}-9.05 \mathrm{GHz}$ for satellite applications, and the proposed antenna is suitable for UWB wireless communication applications.
\end{abstract}

\section{Introduction}

The Federal Communications Commission (FCC) [1] has allocated the spectrum from 3.1 to $10.6 \mathrm{GHz}$ for UWB communication applications in 2002. The UWB communication has attracted much attention owing to their advantages such as high-speed data transfer and low power consumption. As a key part of the communication systems, the UWB antennas have also attracted much attention in industry and academia.

The microstrip UWB antennas have been designed and studied in the past few years. Some different geometries antennas with wide bandwidth have been reported in [2-6]. In [2], a monopole antenna with two parasitic elements and partial ground plane is designed and fabricated at $3.5 \mathrm{GHz}-$ $20 \mathrm{GHz}$ on $30 \times 35 \mathrm{~mm}^{2}$ substrate. In [3], the dimensions of the rectangular ground planes and the split-ring loops are tuned for achieving a very wide bandwidth antenna from $2 \mathrm{GHz}$ to $20 \mathrm{GHz}$. In [4], a miniature crescent-shaped UWB antenna is studied at $3.4 \mathrm{GHz}-20 \mathrm{GHz}$ with only $17 \times 18 \times$ $1.575 \mathrm{~mm}^{3}$. Antenna features a coplanar waveguide single strip terminated with a semielliptic stub and a modified ground plane to achieve bandwidth from $2.85 \mathrm{GHz}$ to $20 \mathrm{GHz}$ with $22.85 \times 21.42 \mathrm{~mm}^{2}$ is presented in [5]. CPW-fed UWB slot antenna is designed which operates at $3 \mathrm{GHz}-20 \mathrm{GHz}$, and its dimension is $63.53 \times 45 \mathrm{~mm}^{2}$ in [6]. From [1-6], the $\mathrm{CPW}$ technology is used, and it reaches $17-18 \mathrm{GHz}$ bandwidth and relatively compact size. Some different geometries antennas with narrow bandwidth are presented in [7-12]. In [7], a CPW-fed compact UWB microstrip antenna with inverted L-shaped technique is presented, which operates at $2.6 \mathrm{GHz}-13.04 \mathrm{GHz}$, and its dimension is $25 \times 25 \times 1.6 \mathrm{~mm}^{3}$.

A planar UWB antenna with a band-notch characteristic is obtained from $3 \mathrm{GHz}$ to $13 \mathrm{GHz}$ on $28 \times 30 \mathrm{~mm}^{2}$ in [8]. In [9] it has a dimension of $30 \times 27 \times 1.6 \mathrm{~mm}^{3}$ and operates at frequencies of $2.7 \mathrm{GHz}-12 \mathrm{GHz}$ with modified slotted ground plane. In [10], the UWB antenna has a big size of $88 \times$ $97 \mathrm{~mm}^{2}$ and operates at frequencies of $3 \mathrm{GHz}-10 \mathrm{GHz}$ with full ground plane. In [11] it has a dimension of only $20 \times$ $20 \mathrm{~mm}^{2}$ and operates from $3.04 \mathrm{GHz}$ to $10.87 \mathrm{GHz}$ by using a coupled rotated C-shaped strip around the inverted T-shaped conductor backed plane. In [12], the UWB slot antenna is presented at $3 \mathrm{GHz}-11.2 \mathrm{GHz}$ on $22 \times 24 \mathrm{~mm}^{2}$ substrate.

In this paper, a novel CPW-fed UWB antenna with bandstop function is presented. The proposed antenna consists of a CPW-fed slot rectangular patch with an open stub ground [13] and two inverted L-shaped strip conductors in the back side plane. Half of ground plane with open stub and a slot rectangular patch are fabricated on the top of the substrate. The other half of ground plane and two inverted L-shaped strip conductors are fabricated on the bottom of the substrate. Simulated and measured results show that this antenna operates at $2.9 \mathrm{GHz}-13.08 \mathrm{GHz}$ with a band rejection performance in the frequency band of $7.7-9.05 \mathrm{GHz}$. The antenna has a relatively small size of $25 \times 25 \times 1.6 \mathrm{~mm}^{3}$. 


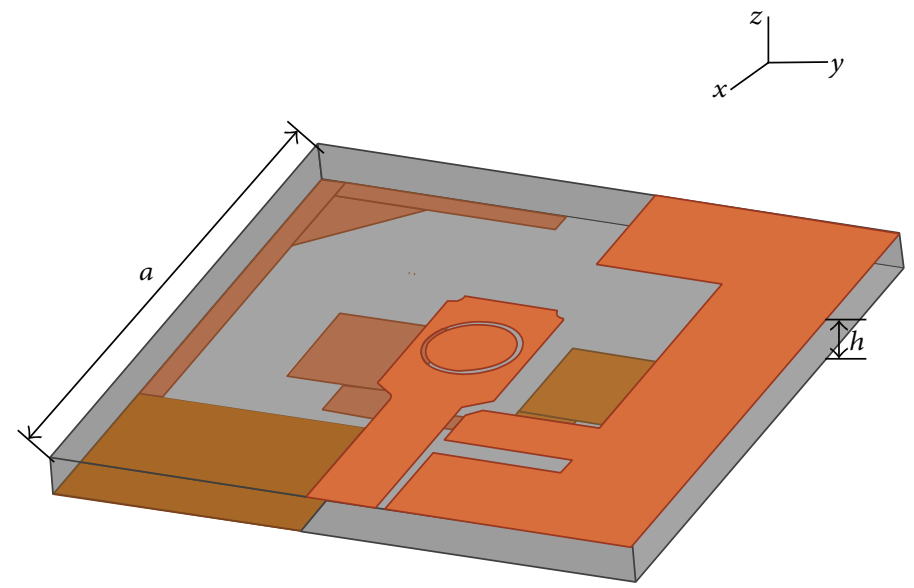

(a)
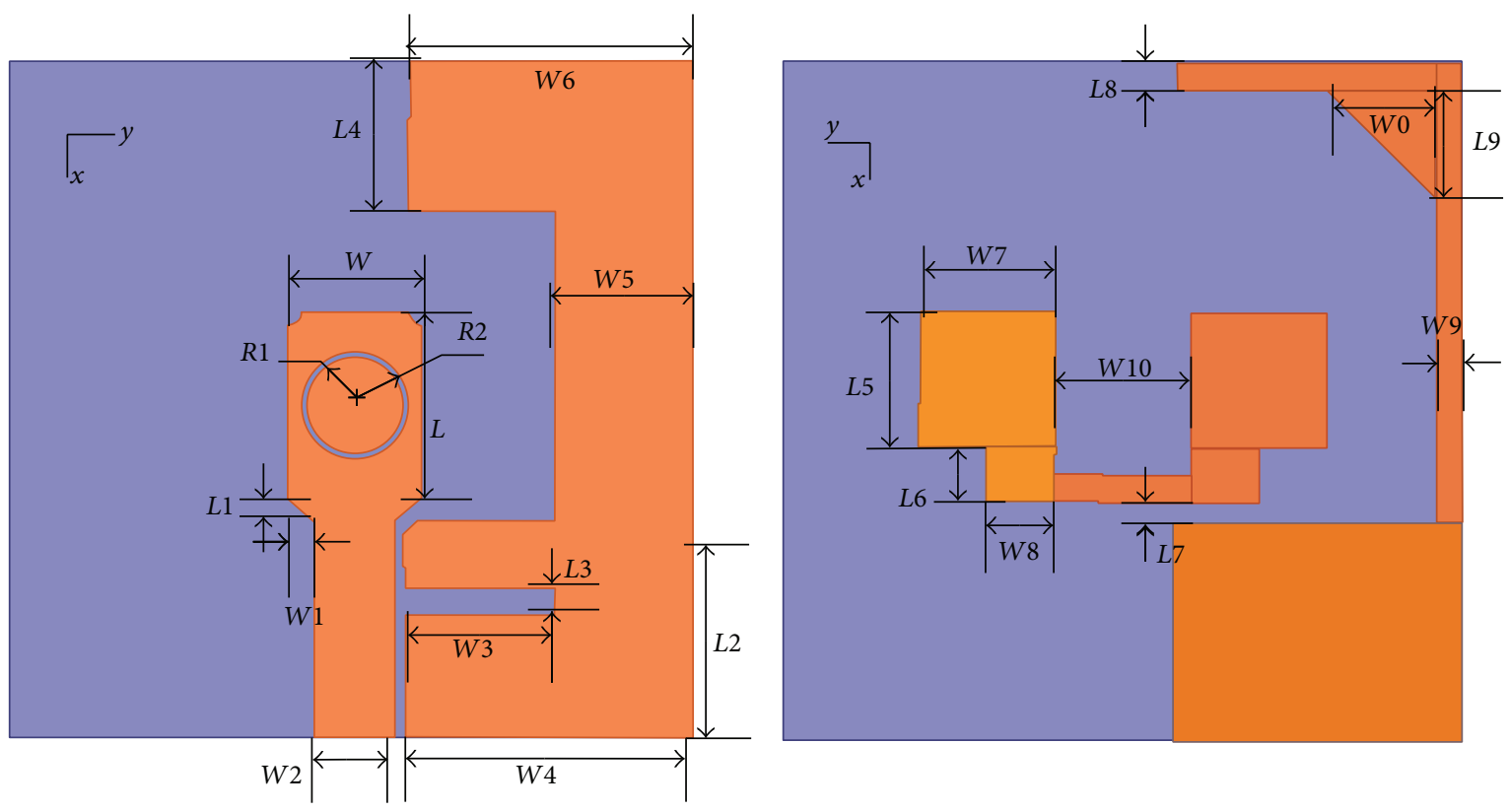

(b)

FIGURE 1: Geometry of the proposed antenna: (a) side view and (b) top view (left) and bottom view (right).

\section{Antenna Design and Analysis}

The geometry of the proposed antenna is shown in Figure 1. A CPW fed with slot rectangular patch is implemented. Half of the ground plane with open stub is fabricated on the top of the substrate. The other half of the ground plane with two inverted L-shaped strip conductors is fabricated on backed plane. The CPW feeding line is designed for $50 \Omega$ independence. The proposed antenna is designed and fabricated on a $1.6 \mathrm{~mm}$ thick FR-4 substrate with permittivity consisting of 4.4 and a loss tangent of 0.024 . The geometric dimensions of the proposed antenna are summarized in Table 1.

The traditional antennas without slot rectangular patch or without open stub ground plane are presented in Figure 2. To further illustrate the advantage of the proposed antenna with slot rectangular patch and open stub ground plane, the comparisons of return losses and VSWR of the three kinds of antennas are shown in Figures 3 and 4, respectively. Worse matching condition in the UWB band, especially the upper band, is the main problem of the conventional rectangular patch antenna without open stub plane ground. The conventional rectangular patch antenna without slot has relatively good matching condition; however, the resonant mode of this kind of antenna in the upper band is not clear. A very well matching condition over the UWB band for the proposed antenna is obvious; moreover, the band injection in the frequency band of 7.7-9.05 GHz is achieved.

In Figure 5, the simulated results of the proposed antenna with the width of slot changing from $0.2 \mathrm{~mm}$ to $0.6 \mathrm{~mm}$ ( $S=$ $R_{2}-R_{1}$ ) have been presented. It can be seen that the return losses $S_{11}<10 \mathrm{~dB}$ in all UWB band. From Figure 5, it is also clear that the width of slot has less influence on the bandwidth of return losses; however, when the width of slot $S$ decreases, 


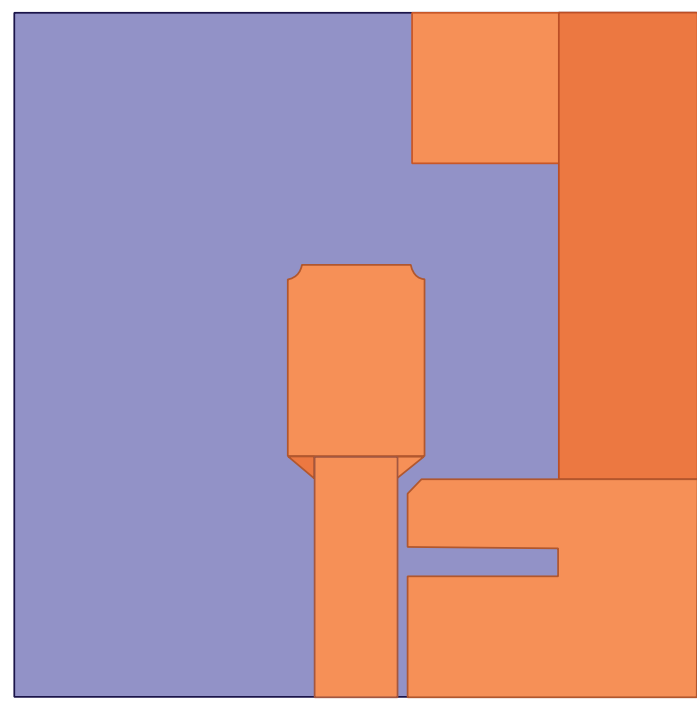

Without slot

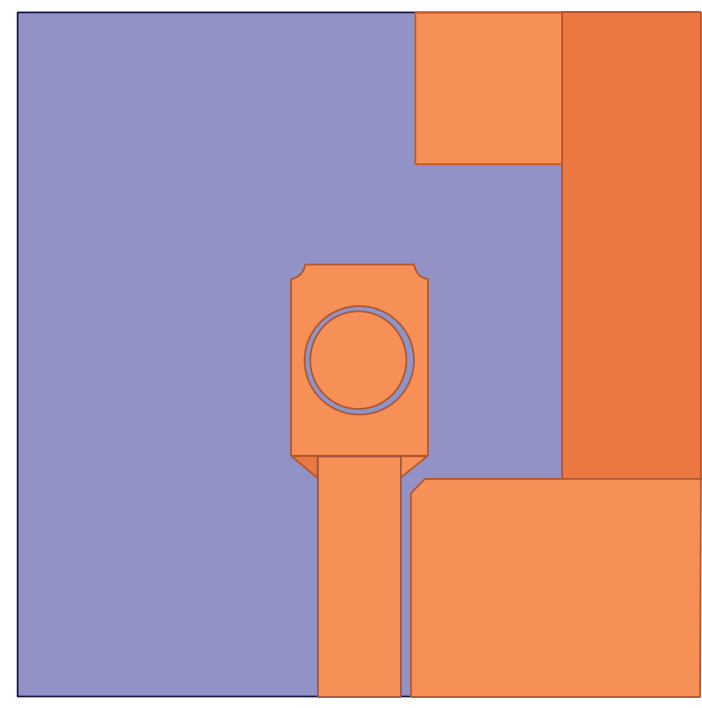

Without open stub

FIGURE 2: The proposed antenna without slot and without open stub.

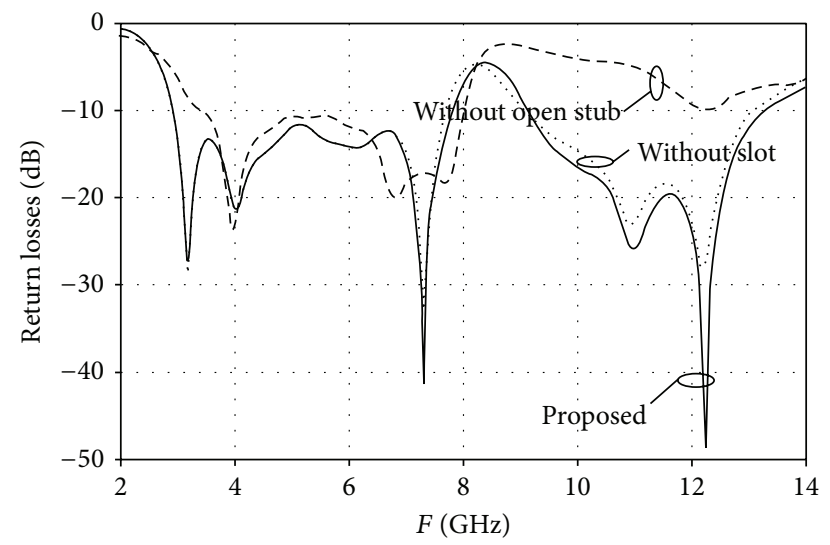

FIGURE 3: Simulated return losses of the proposed antenna, without open stub antenna, and without slot antenna.

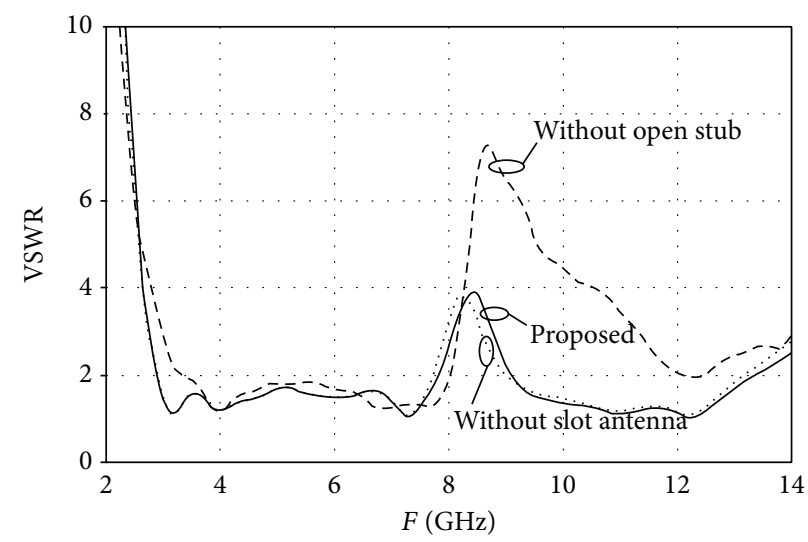

FIGURE 4: Simulated VSWR of the three kinds of antennas: proposed, without open stub, and without slot antennas.

TABLE 1: Design parameters of the proposed UWB antenna.

\begin{tabular}{lccccccccccccccccccccccccccc}
\hline Parameters $a$ & $h$ & $W$ & $W 0$ & $W 1$ & $W 2$ & $W 3$ & $W 4$ & $W 5$ & $W 6$ & $W 7$ & $W 8$ & $W 9$ & $W 10$ & $L$ & $L 1$ & $L 2$ & $L 3$ & $L 4$ & $L 5$ & $L 6$ & $L 7$ & $L 8$ & $L 9$ & $R 1$ & $R 2$ \\
\hline Unit $(\mathrm{mm})$ & 25 & 1.6 & 5 & 4 & 1 & 3 & 5.5 & 10.6 & 5.1 & 10.5 & 5 & 2.5 & 1 & 5 & 7 & 0.8 & 8 & 1 & 5.5 & 5 & 2 & 0.8 & 1 & 4 & 1.8 & 2 \\
\hline
\end{tabular}




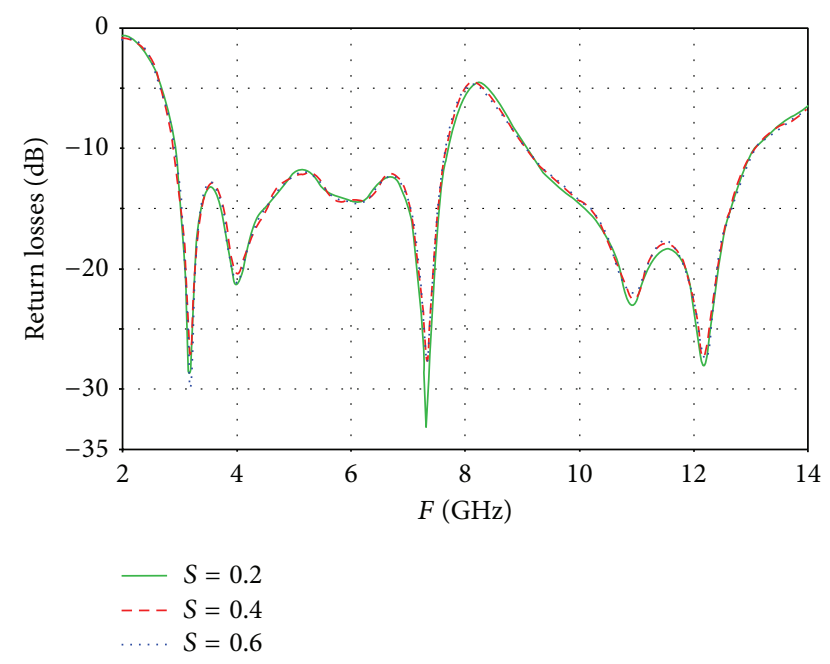

FIGURE 5: Simulated return losses of the proposed UWB antenna with different $S$.

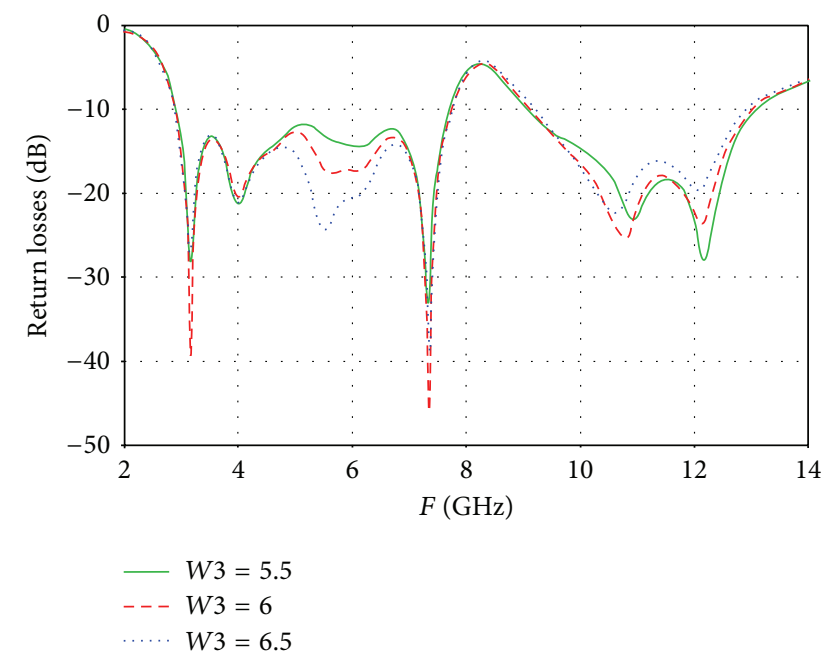

FIGURE 6: Simulated return losses of the proposed UWB antenna with different $W 3$.

the antenna has better matching condition, especially in the resonant frequency.

Through the above analysis and computer simulation with HFSS, the optimum width of slot $S$ is $0.2 \mathrm{~mm}(S=$ $R_{2}-R_{1}, R_{2}=2.0 \mathrm{~mm}$ and $R_{1}=1.8 \mathrm{~mm}$ ).

Figure 6 presents the simulated results of the proposed antenna with the length of open stub $W 3$ changing from $5.5 \mathrm{~mm}$ to $6.5 \mathrm{~mm}$. It is obvious that when the length $W 3$ increases, the lower band becomes much flatter and the upper band becomes much steeper, especially for the high resonant frequencies. So, the optimum length of stub $W 3$ is chosen as $5.5 \mathrm{~mm}$.

Figure 7 presents the simulated results of the proposed antenna with the width of the open stub $L 3$ changing from $1 \mathrm{~mm}$ to $2 \mathrm{~mm}$. From Figure 7, it is clear that when the width of $L 3$ increases, the matching performance of the upper

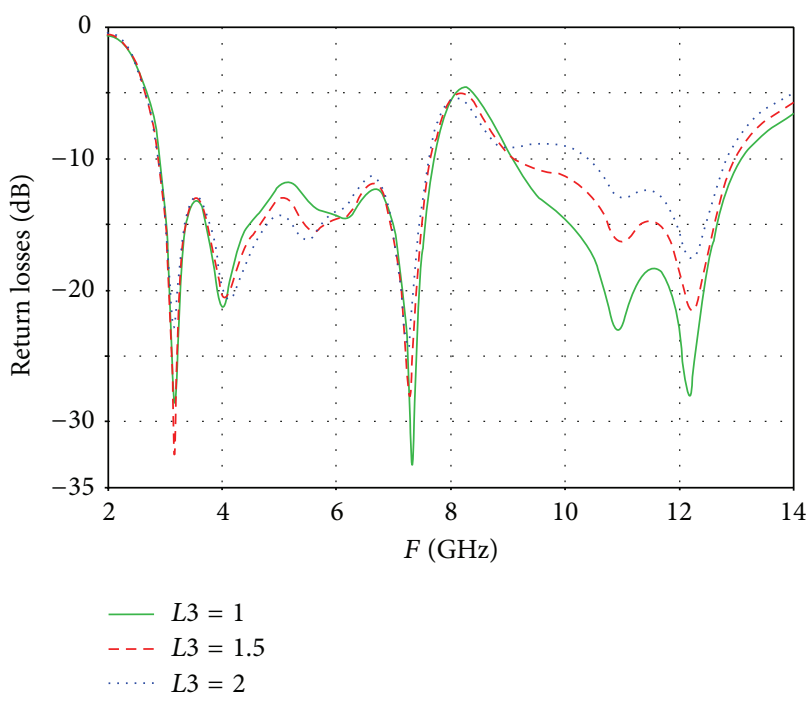

FIGURE 7: Simulated return losses for the proposed UWB antenna with different $L 3$.

band of the antenna has distinctly improved. Therefore, the optimum width of open stub $L 3$ is chosen as $1 \mathrm{~mm}$.

The 3D far-field radiation patterns of the proposed UWB antenna at specific frequencies using CST software are shown in Figure 8. From Figure 8, it is obvious that the proposed UWB antenna has acceptable quasi-omnidirectional radiation patterns to receive external signals from all directions.

\section{Results and Discussion}

The Agilent vector network analyzer has been used to measure the return losses, VSWR, and radiation gain of the proposed antenna.

Figure 9 is the measured and simulated results of return losses of the proposed antenna. It is clear that the measured and simulated results show that the designed antenna operates at $2.9 \mathrm{GHz}-13.08 \mathrm{GHz}$ with band rejection performance in the frequency band of $7.7 \mathrm{GHz}-9.05 \mathrm{GHz}$, and a good agreement between the measured and simulated results is observed.

In Figure 10, the measured and simulated VSWR for the proposed antenna have been described. From Figure 10, we can see that the VSWR of the operating frequencies band for the proposed antenna is less than 2 and the VSWR of band rejection for the proposed UWB antenna is more than 2 .

Figure 11 presents the simulated and measured radiation gain of the proposed antenna. A relatively high radiation gain has been obtained from $2.9 \mathrm{GHz}$ to $13.08 \mathrm{GHz}$. It can be seen in Figure 11 that the antenna has a sharp radiation gain decrease at the notch frequency band of $9.0 \mathrm{GHz}$ and the radiation gain outside of the notch frequency band is unaffected.

Figure 12 shows the measured radiation patterns including the copolarization and cross-polarization in E-plane and $\mathrm{H}$-plane at specific frequencies. It can been seen that the proposed UWB antenna has good omnidirectional radiation 


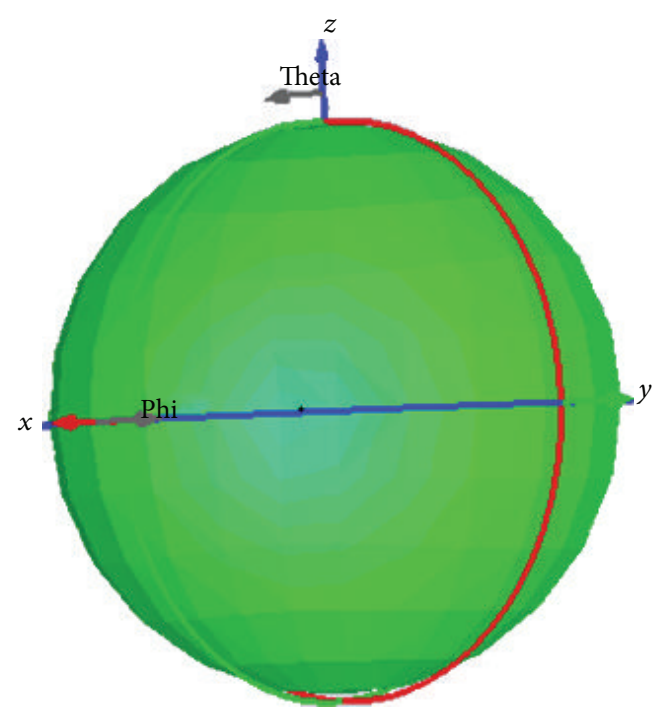

(a)

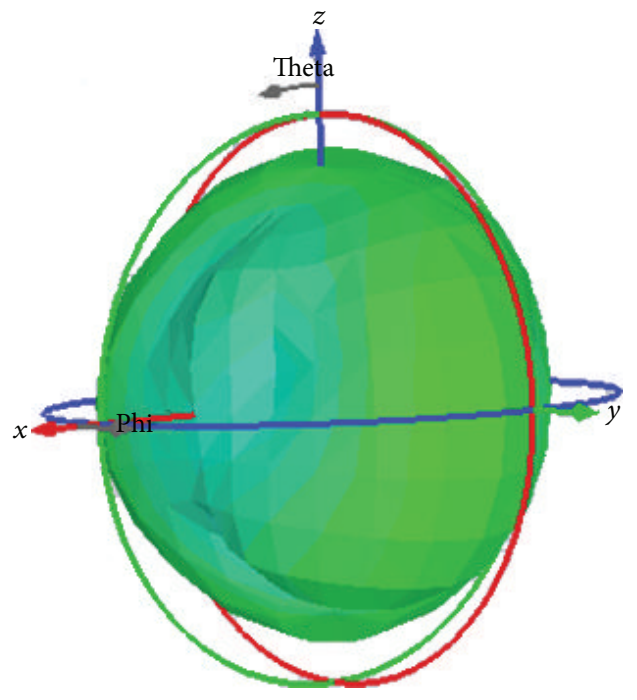

(c)

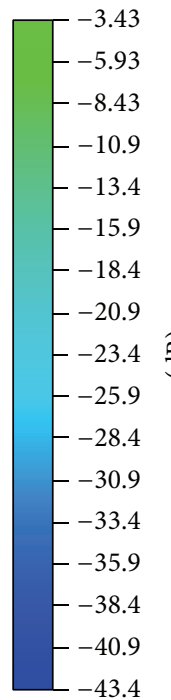

$-43.4$

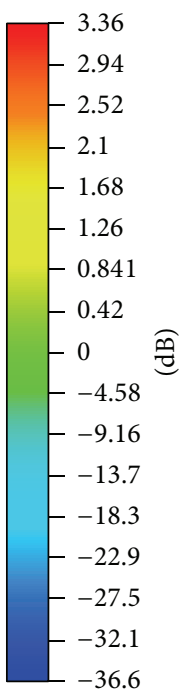

$-36.6$

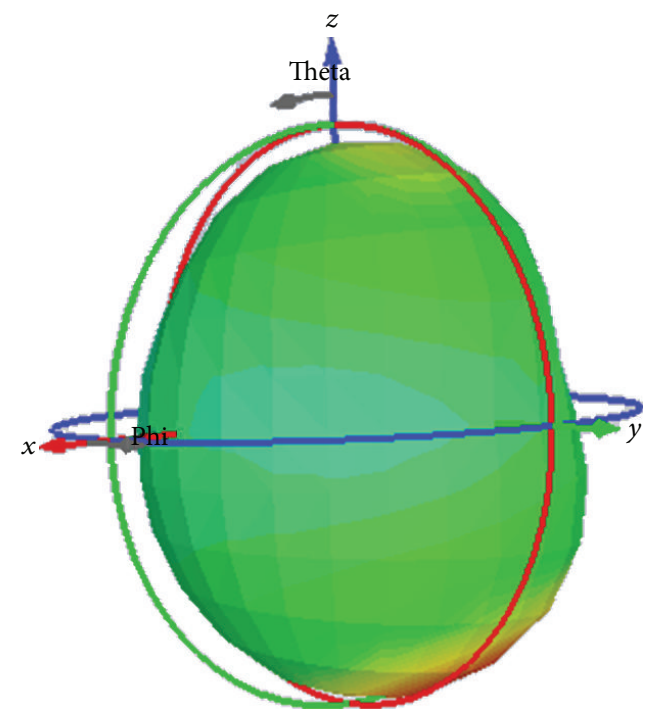

(b)

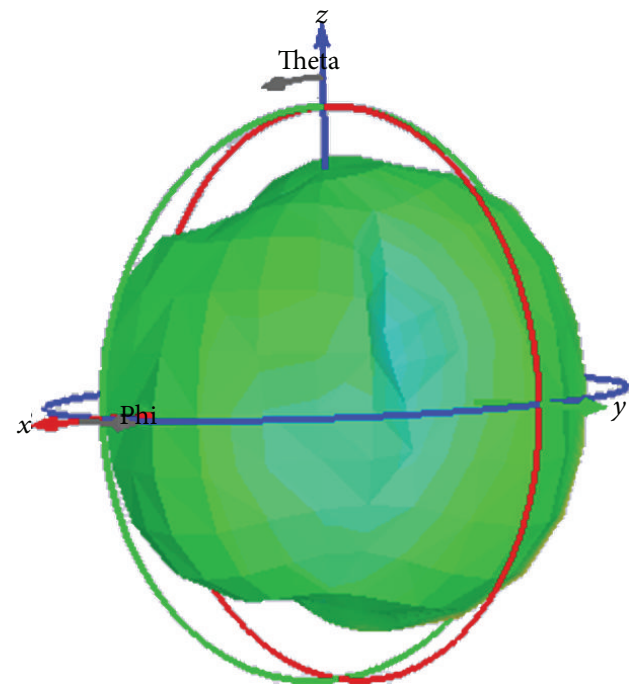

(d)

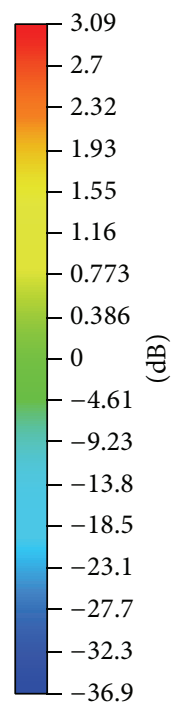

$-36.9$

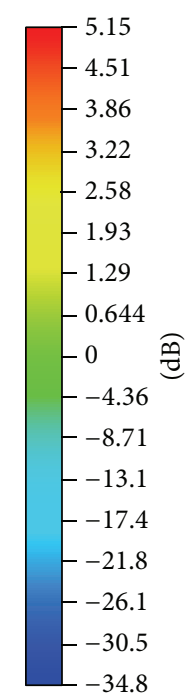

FIGURE 8: Simulated 3D far-field radiation patterns at specific frequencies: (a) $3.17 \mathrm{GHz}$, (b) $7.32 \mathrm{GHz}$, (c) $9.97 \mathrm{GHz}$, and (d) $12.16 \mathrm{GHz}$.

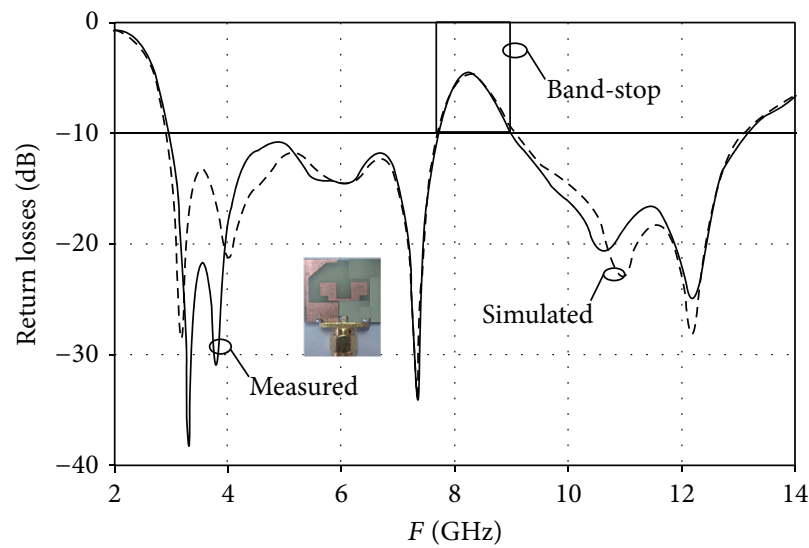

Figure 9: Measured and simulated return losses of the proposed antenna. 


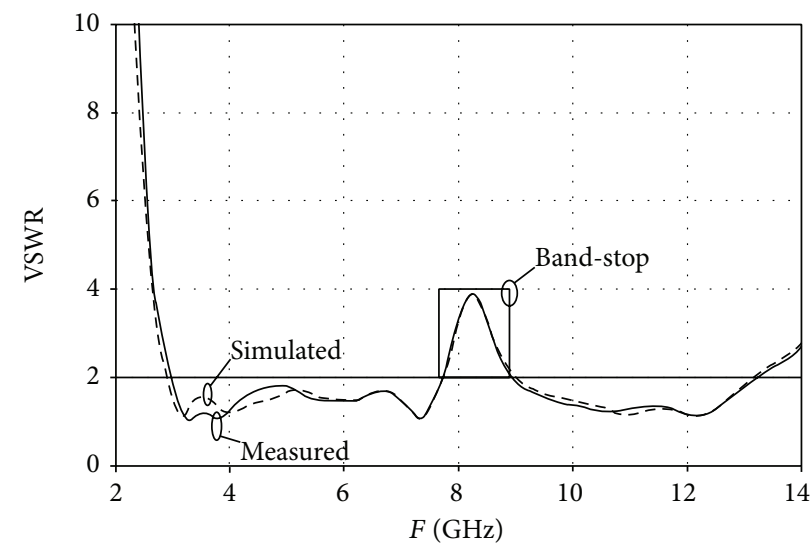

FIGURE 10: Measured and simulated VSWR of the proposed antenna.

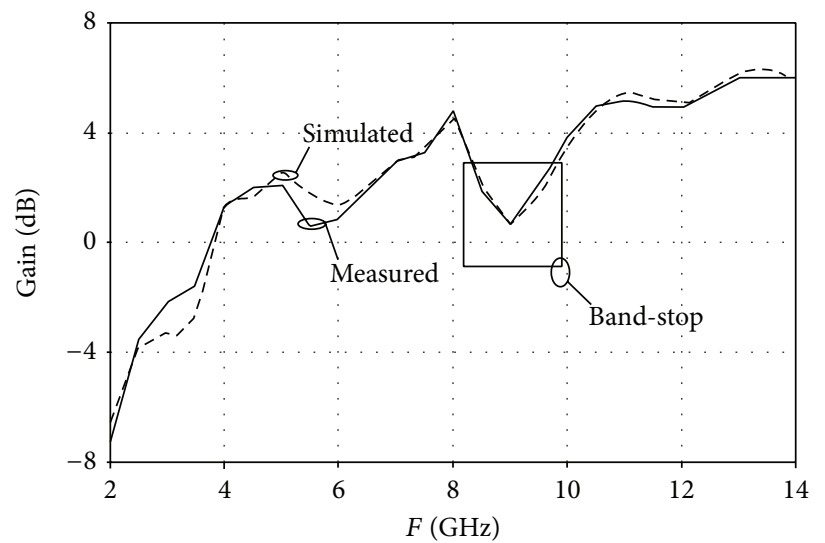

FIGURE 11: Measured and simulated radiation gain of the proposed antenna.

patterns at $3.17 \mathrm{GHz}, 7.32 \mathrm{GHz}, 9.97 \mathrm{GHz}$, and $12.16 \mathrm{GHz}$, respectively.

At last, this antenna is compared with some different UWB antennas to exhibit the advantages of slot patch and open stub ground. The detailed figure of merit parameters are summarized in Table 2. The radiation gain of the proposed antenna is from $-1.82 \mathrm{dBi}$ to $8.7 \mathrm{dBi}$ in the UWB frequency band. Moreover, the size of proposed antenna is $25 \times 25 \times$ $1.6 \mathrm{~mm}^{3}$, and it is relatively small. So, it is obvious that the proposed UWB antenna has advantages on the radiation gain and size more than those of the other reported works.

\section{Conclusion}

In this paper, we present a novel CPW-fed UWB antenna with band-stop function. Some key parameters have been investigated. Improved performances of the proposed antenna have been obtained by using slot patch, open stub ground, and two L-shaped strip conductors in ground plane. The simulated and measured results indicate that the proposed antenna offers an operating bandwidth of $2.9-13.08 \mathrm{GHz}$ with band rejection of 7.7-9.05 GHz. Meanwhile, fidelity evaluated that the antenna exhibits an impressive radiation response, which
TABLE 2: Figure of merit comparison of some differential antennas.

\begin{tabular}{lcccc}
\hline Antenna & $\begin{array}{c}\text { Bandwidth } \\
(\mathrm{GHz})\end{array}$ & $\begin{array}{c}\text { Band-stop } \\
(\mathrm{GHz})\end{array}$ & $\begin{array}{c}\text { Size } \\
\left(\mathrm{mm}^{2}\right)\end{array}$ & $\begin{array}{c}\text { Gain } \\
(\mathrm{dB})\end{array}$ \\
\hline This work & $2.9-13.08$ & $7.7-9.05$ & $25 \times 25$ & $-3.32-6.2$ \\
{$[8]$} & $3.0-13$ & $5.0-6.0$ & $28 \times 30$ & $0.2-3.9$ \\
{$[9]$} & $2.7-12$ & None & $30 \times 27$ & $0.2-2.5$ \\
{$[11]$} & $3.04-10.87$ & $5.03-5.94$ & $20 \times 20$ & $-0.5-1.5$ \\
\hline
\end{tabular}

makes it a promising candidate for future UWB wireless communication systems.

\section{Conflict of Interests}

The authors declare that there is no conflict of interests regarding the publication of this paper.

\section{Acknowledgments}

The authors would like to thank Dr. Professor Jit S. Mandeep and the anonymous reviewers for providing valuable comments which helped in improving this paper. 


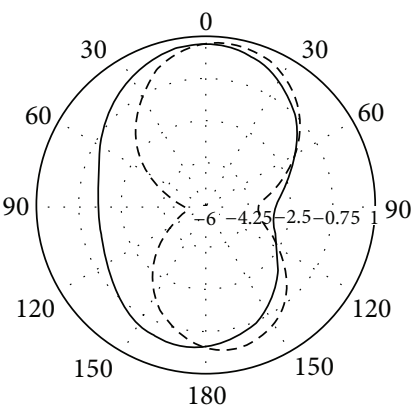

(a)

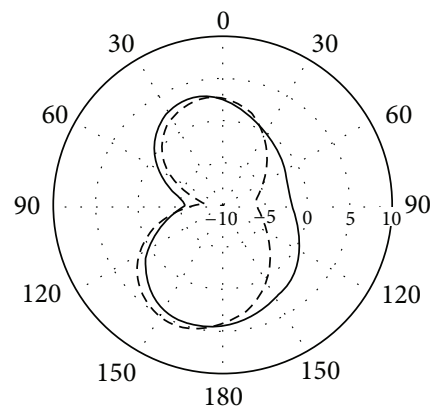

(c)

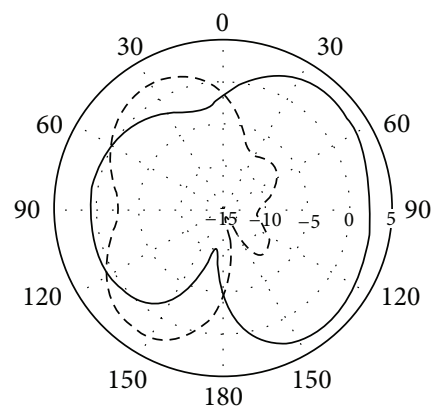

(e)

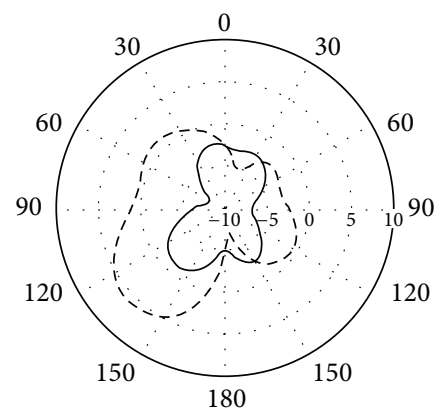

- Co.
-- Cross

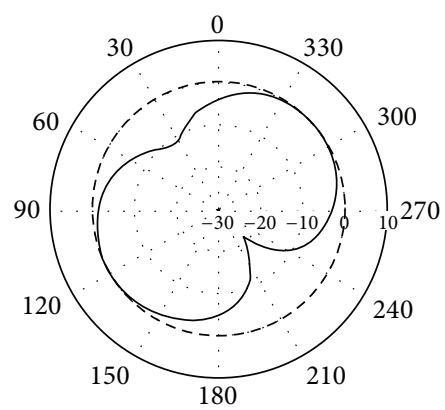

(b)

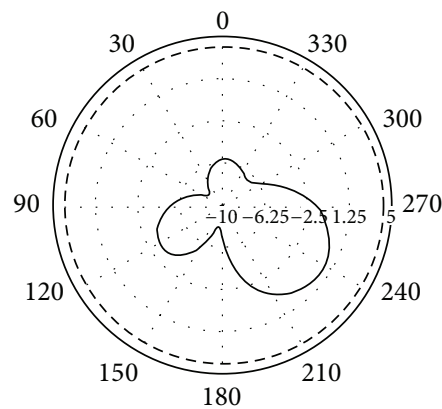

(d)

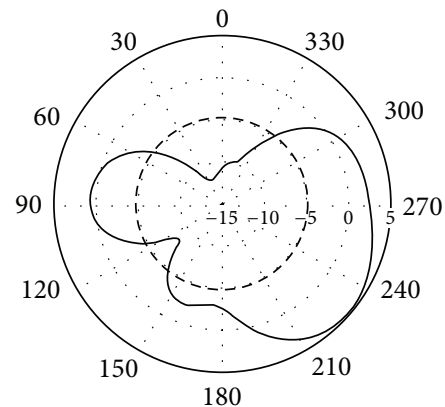

(f)
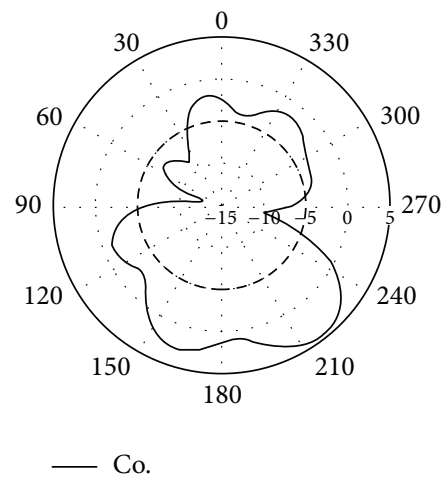

- - Cross

(g)

(h)

Figure 12: Measured E-plane (a, c, e, and g) and H-plane (b, d, f, and h) of the proposed antenna: (a, b) $3.17 \mathrm{GHz},(\mathrm{c}, \mathrm{d}) 7.32 \mathrm{GHz},(\mathrm{e}, \mathrm{f})$ 9.97 GHz, and (g, h) $12.16 \mathrm{GHz}$. 


\section{References}

[1] Communications Commission, First report and order, revision of part 15 of Commission's rule regarding UWB transmission system FCC02-48, 2002.

[2] Z. F. Elsharkawy, A. A. Sharshar, S. M. Elhalafawy, and S. M. Elaraby, "Ultra-wideband A-shaped printed antenna with parasitic elements," Journal of Electromagnetic Waves and Applications, vol. 24, no. 14-15, pp. 1909-1919, 2010.

[3] G. M. Yang, R. H. Jin, G. B. Xiao, C. Vittoria, V. G. Harris, and N. X. Sun, "Ultrawideband (UWB) antennas with multiresonant split-ring loops," IEEE Transactions on Antennas and Propagation, vol. 57, no. 1, pp. 256-260, 2009.

[4] C. M. Dikmen and G. Çakir, "Miniature crescent shaped UWB antenna," International Journal of RF and Microwave ComputerAided Engineering, vol. 23, no. 4, pp. 494-498, 2013.

[5] M. Gopikrishna, D. D. Krishna, C. K. Anandan, P. Mohanan, and V. Vasudevan, "Design of a compact semi-elliptic monopole slot antenna for UWB systems," IEEE Transactions on Antennas and Propagation, vol. 57, no. 6, pp. 1834-1837, 2009.

[6] Y. C. Lee, S. C. Lin, and J. S. Sun, "CPW-fed UWB slot antenna," in Proceedings of the Asia Pacific Conference, pp. 1636-1639, Yokohama, Japan, December 2006.

[7] A. K. Gautam, S. Yadav, and B. K. Kanaujia, "A CPW-fed compact UWB microstrip antenna," IEEE Antennas and Wireless Propagation Letters, vol. 12, pp. 151-154, 2013.

[8] F. Yu and C. Wang, "A CPW-fed novel planar ultra-wideband antenna with a band-notch characteristic," Radioengineering, vol. 18, no. 4, pp. 551-555, 2009.

[9] S. Jacob, V. A. Shameena, S. Mridula, C. K. Anandan, K. Vasudevan, and P. Mohanan, "Planar UWB antenna with modified slotted ground plane," International Journal of RF and Microwave Computer-Aided Engineering, vol. 22, no. 5, pp. 594602, 2012.

[10] P. B. Samal, P. J. Soh, and G. A. E. Vandenbosch, "UWB alltextile antenna with full ground plane for off-body WBAN communications," IEEE Transactions on Antennas and Propagation, vol. 62, no. 1, pp. 102-108, 2014.

[11] M. Ojaroudi and N. Ojaroudi, "Ultra-wideband small rectangular slot antenna with variable band-stop function," IEEE Transactions on Antennas and Propagation, vol. 62, no. 1, pp. 490-494, 2014.

[12] R. Azim, M. T. Islam, and N. Misran, "Compact taperedshape slot antenna for UWB applications," IEEE Antennas and Wireless Propagation Letters, vol. 10, pp. 1190-1193, 2011.

[13] T. Kodera and C. Caloz, "Uniform ferrite-loaded open waveguide structure with CRLH response and its application to a novel backfire-to-endfire leaky-wave antenna," IEEE Transactions on Microwave Theory and Techniques, vol. 57, no. 1, pp. 784-795, 2009. 

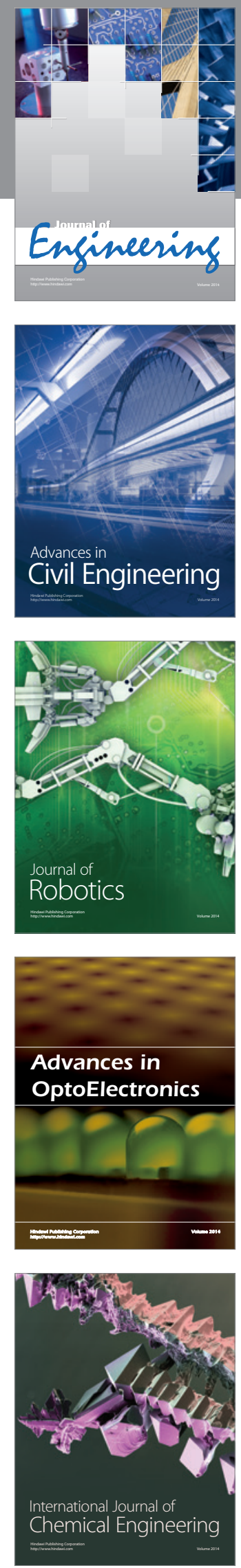

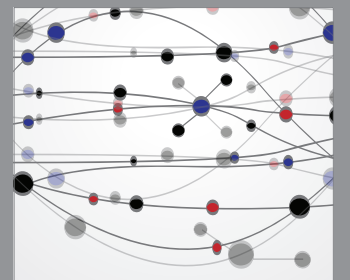

The Scientific World Journal
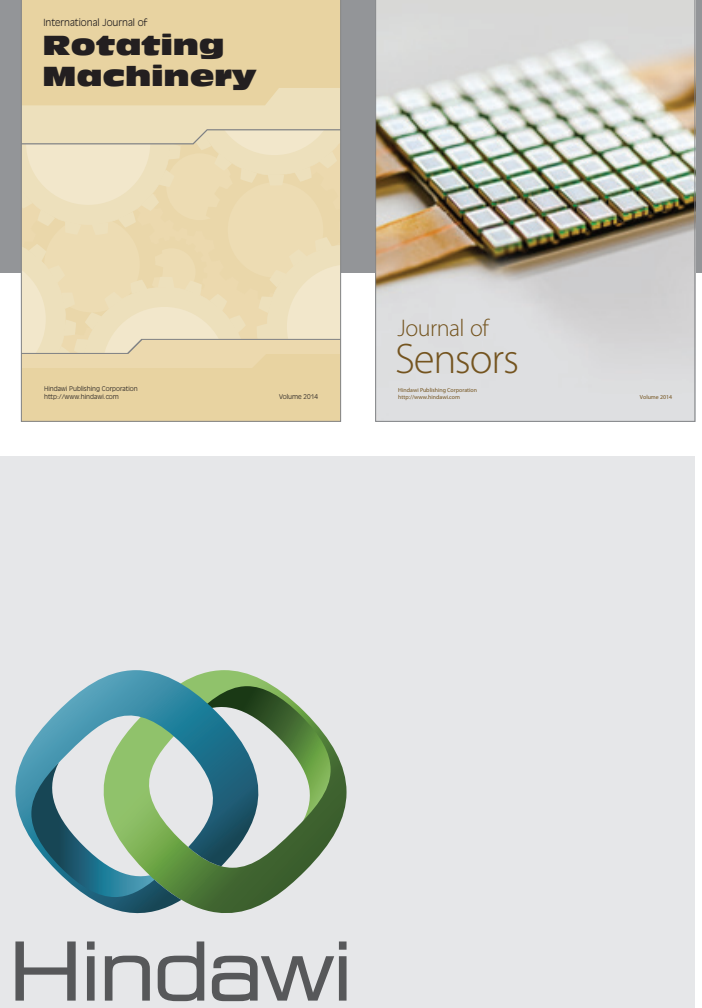

Submit your manuscripts at http://www.hindawi.com
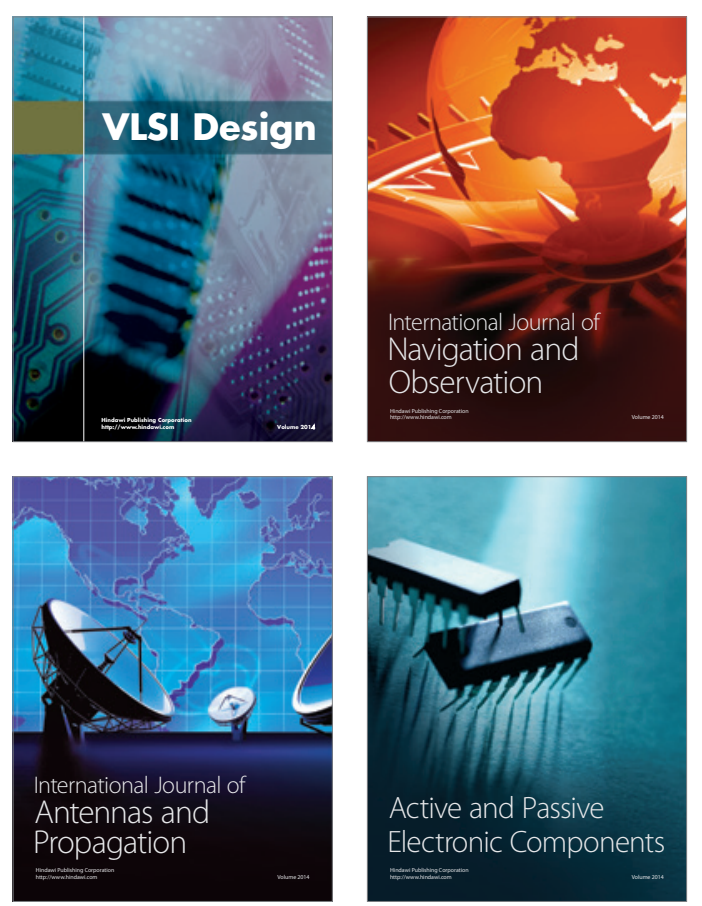
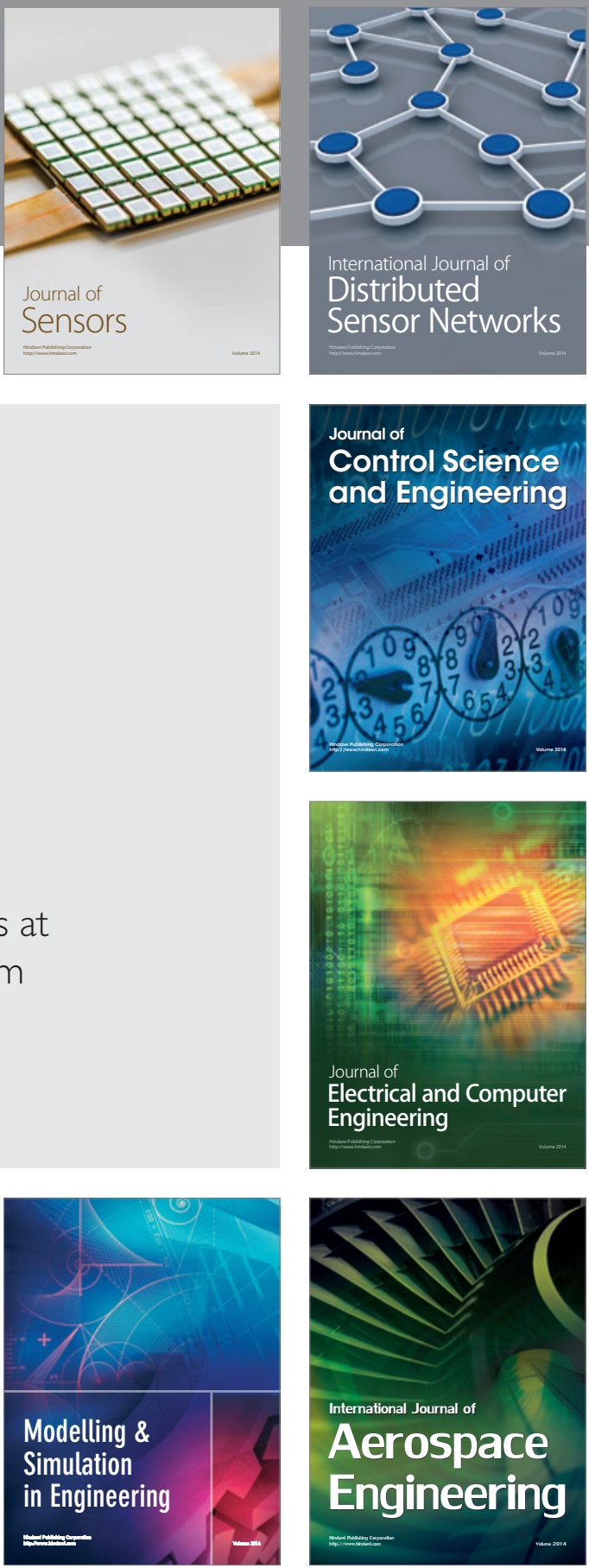

Journal of

Control Science

and Engineering
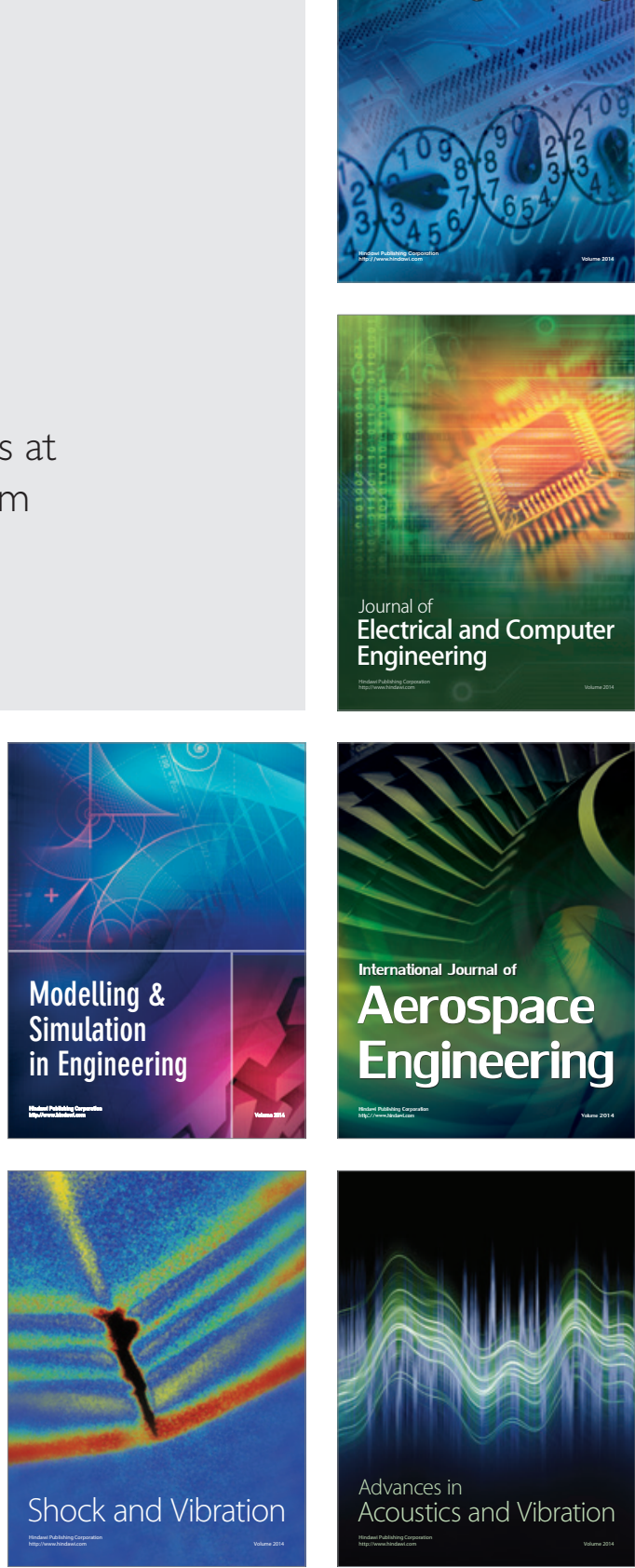